\title{
RESEARCH
}

Open Access

\section{Sociodemographic inequities in dental care utilisation among governmental welfare recipients in Japan: a retrospective cohort study}

Daisuke Nishioka ${ }^{1,2,3}$, Keiko Ueno ${ }^{2,3}$, Shiho Kino ${ }^{2,3}$, Jun Aida ${ }^{4,5}$ and Naoki Kondo ${ }^{2,3,6,7^{*}}$ (D)

\begin{abstract}
Background: Maintaining oral health is one of the global public health challenges. Income and out-of-pocket payments for dental care services are predictors of dental care utilisation. Although public assistance programmes guarantee income security for impoverished people, access barriers other than financial costs may cause unmet dental care needs. We aimed to explore the potential sociodemographic factors determining dental care utilisation among recipients of public assistance in Japan using linkage data of public assistance database and medical assistance claim data administered by municipalities.
\end{abstract}

Methods: This was a retrospective cohort study involving a sample of public assistance recipients. We extracted the recipients' sociodemographic data (age, sex, household number, employment status, nationality, disability certificates, and long-term care status) in January 2016 and observed them until December 2016 to identify incidences of dental care utilisation as outcomes. We performed a multivariable modified Poisson regression analysis with a robust standard error estimator to calculate the incidence ratio (IR) of dental care utilisation in each variable.

Results: We identified a total of 4497 recipients at risk. Among them, 839 recipients used dental care services. Younger age was associated with a higher incidence of dental care utilisation. The female recipients had a higher incidence of dental care utilisation when compared to the male ones (adjusted IR, 1.22; 95\% confidence interval $[\mathrm{Cl}], 1.08-1.38)$. Immigrant recipients had a higher incidence of dental care utilisation than the Japanese ones (IR, 1.53; 95\% Cl, 1.16-2.01). Recipients with mental disabilities had higher incidences than those without disability certificates (IR, 1.30; 95\% Cl, 1.08-1.56).

Conclusions: Non-financial sociodemographic inequities in dental care utilisation stemming from age, sex, nationality, and presence of mental disability were found despite minimum income protection and equitable financial dental service access amongst public assistance recipients in Japan. Providing targeted preventive care and treatments for dental care among underserved populations is required to tackle oral health inequities.

Keywords: Poverty, Oral health inequities, Public assistance, Free dental care access, Japan

\footnotetext{
* Correspondence: kondo.naoki.0s@kyoto-u.ac.jp

${ }^{3}$ Department of Social Epidemiology, Graduate School of Medicine and School of Public Health, Kyoto University, Floor 2, Science Frontier Laboratory, Yoshida-konoe-cho, Sakyo-ku, Kyoto-shi, Kyoto 606-8315, Japan Full list of author information is available at the end of the article
}

C C The Author(s). 2021 Open Access This article is licensed under a Creative Commons Attribution 4.0 International License, which permits use, sharing, adaptation, distribution and reproduction in any medium or format, as long as you give appropriate credit to the original author(s) and the source, provide a link to the Creative Commons licence, and indicate if changes were made. The images or other third party material in this article are included in the article's Creative Commons licence, unless indicated otherwise in a credit line to the material. If material is not included in the article's Creative Commons licence and your intended use is not permitted by statutory regulation or exceeds the permitted use, you will need to obtain permission directly from the copyright holder. To view a copy of this licence, visit http://creativecommons.org/licenses/by/4.0/. The Creative Commons Public Domain Dedication waiver (http://creativecommons.org/publicdomain/zero/1.0/) applies to the data made available in this article, unless otherwise stated in a credit line to the data. 


\section{Background}

Oral diseases (such as dental caries and periodontal diseases) include a range of chronic clinical conditions that affect the teeth and mouth [1,2]. Although preventable, oral diseases are highly prevalent throughout life. Therefore, oral diseases are major global public health issues and have substantial adverse effects on an individual's physical and mental health, further burdening the society $[1-5]$.

As poverty is a strong determinant of oral health, governments in many countries have welfare programmes, which provide financial support to the poor, and the services include full or partial exemptions of dental care costs [6]. However, even though access to dental care services is ensured, previous studies have reported that other non-financial sociodemographic factors such as sex, marital status, race/ethnicity, nationality, education, job status, and social relationships are also associated with oral health [7-15]. In Japan, there is a governmental welfare programme called public assistance 'seikatsuhogo' that is eligible for households living below the poverty line without any assets. Households on public assistance receive monthly minimum income benefits and are fully exempted from paying for dental care [16]. However, given the potential effects of non-financial socioeconomic statuses on poor oral health, the financial welfare programme may not fully compensate for the socioeconomic risks associated with poor oral health.

Nonetheless, to the best of our knowledge, no study has investigated the potential factors determining dental care utilisation among the impoverished population supported by the Japanese governmental welfare programme. Therefore, the purpose of this study was to explore the sociodemographic determinants of dental care utilisation among public assistance recipients using the linkage data of the municipal public assistance database and the medical assistance claim data in Japan.

\section{Methods}

\section{Study design and participants}

This retrospective cohort study included all adults who received public assistance in two suburban municipalities, Osaka and Tokyo, in January 2016. In Japan, approximately $2 \%$ of the population receives public assistance [16]. Households eligible for public assistance receive monthly minimum income benefits and are fully exempted from paying for medical and dental care [16]. All the public assistance recipients could use the medical assistance programme (including payment for dental care) if they had medical-care vouchers (iryo-ken) from the welfare office. We excluded the data of participants who stopped receiving public assistance during the observational period, which occurred mainly due to participants' increased incomes or deaths (Fig. 1).

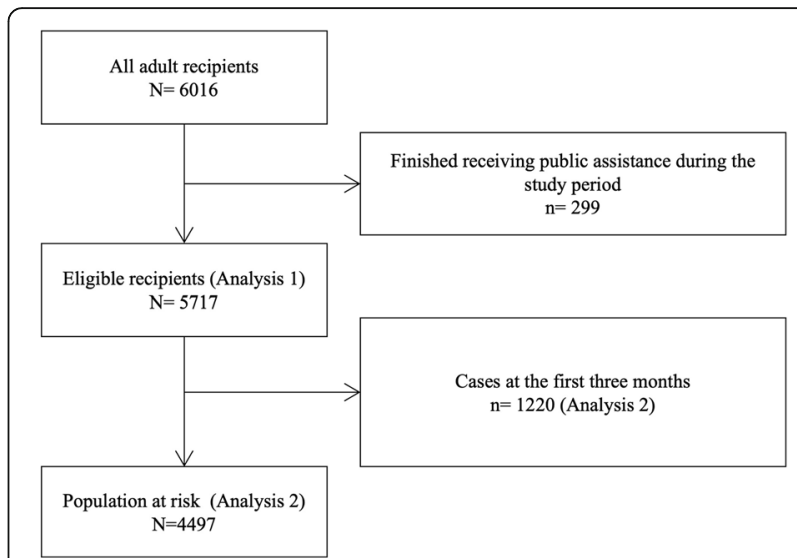

Fig. 1 Flow-chart of study participants

\section{Data sources}

For the baseline data, we used the public assistance recipients' database from the welfare offices of two municipalities (A/B). In 2016, the population of municipality A was approximately 170,000 people, $23.7 \%$ of the population was over 65 years old, and $2.8 \%$ of the population was receiving public assistance. The financial index of municipality A was 1.1 , and the unemployment rate was $4.3 \%$. In contrast, the population of municipality B was approximately 100,000 people, $24.7 \%$ of the population was over 65 years old, and $1.8 \%$ of the population was receiving public assistance. The financial index of municipality B was 0.9 , and the unemployment rate was $5.1 \%$. The financial index is expressed as a ratio of total revenues to total expenditures in the municipality within three years; an index of less than one indicates that the municipality's finances are in deficit. The average value of the financial index among all the Japanese municipalities was 0.50 , which means the municipalities included in this study were relatively financially independent [17].

The public assistance database included information on age, sex, number of family members, household composition, nationality, working status, and income, including work income, pension, and disability pension. These data were collected by the staff of the municipality welfare offices to determine the utilisation of public assistance and the amount of monthly minimum income protection; thus, we did not have any missing data. To obtain the outcome data, we used medical assistance claim data between January, 2016 and December, 2016, which included dental claim data. The data comprised the recipients' monthly medical and dental consultations, total consultation cost, total number of visits each month, and diagnoses.

Each municipality linked the two databases using individual identification codes. The welfare offices of the two municipalities agreed to provide anonymised data to the authors via a system company that provided the 
management software of the public assistance database to the municipalities. This study protocol was approved by the Ethics Committee of the Graduate School of Medicine of the University of Tokyo (Approval No: 11503).

\section{Measurements and variables Outcome variables}

From the medical assistance claim data, we identified the cumulative incidence of dental care utilisation, defined as receiving dental care services for the following oral diseases once or multiple times during the observational period: $\mathrm{K} 00$, disorders of tooth development and eruption; K01, embedded and impacted teeth; K02, dental caries; K03, other diseases of hard tissues of teeth; K04, diseases of pulp and periapical tissues; K05, gingivitis and periodontal diseases; and $\mathrm{K} 06$, other disorders of gingiva and edentulous alveolar ridge. These oral diseases were determined according to the International Classification of Disease, Tenth Edition (ICD-10) code [18]. These variables were considered as proxy measures of poor dental health conditions and accessibility to dental care services. We dichotomized the cumulative incidence of dental care utilisation into a binary variable exhibiting dental care utilisation or not.

\section{Explanatory variables}

Based on the data availability as of January 2016, we extracted the following information as demographic factors: age (continuous), sex (female or male), household composition (living alone or not), employment status (working or not), and nationality (Japanese or others). Since recipients of disability assistance can receive additional income and social care benefits, we considered mental, intellectual, and physical disabilities as potential confounding factors by noting information on the qualifications for welfare benefits for disabled people, as municipality officials certify them with the diagnosis given by designated physicians. We also adjusted for the levels of long-term care needs based on the information in the public long-term care insurance system. In the system, there are seven nationally standardised levels of longterm care need (support requirement levels 1 and 2, and care need levels 1 to 5) [16]. People aged 65 years and above who are potentially in need of long-term care and people aged 40 years and above with the designated diseases can apply for insurance benefits. Based on the definition of the level, insurers (in most cases, municipality governments) assess and certify the insurance benefits. The benefits provided to the recipient are determined based on the certified level. In this study, we classified the levels into 'support requirement' level and 'care need' level. We coded municipality as a dummy variable to adjust for the cluster structures and unmeasured cultural and environmental characteristics of the two municipalities $(\mathrm{A} / \mathrm{B})$.

\section{Statistical analysis}

First, we described the characteristics of all the study participants and recipients who received dental care during the observation period. Second, we performed a univariable modified Poisson regression analysis which can estimate relative risks of each explanatory variable on binary outcome variable [19], and calculated the crude cumulative incidence ratio (IR) of dental care utilisation and $95 \%$ confidence interval (CI) of each explanatory variable. Third, we performed a multiple modified Poisson regression analysis to calculate the multivariableadjusted IR of each explanatory variable (Analysis 1). To identify the incidence of dental care service utilisation amongst the population at risk, we performed an additional analysis, which excluded recipients who had received dental care in the first three months (Analysis 2). This allowed us to exclude recipients who used dental care services regularly for preventive and treatment measures because their dental care utilisation would have occurred frequently during these three months [20, 21]. Consequently, we could verify the actual incidence of dental care utilisation among the study participants. Furthermore, we performed two sensitivity analyses. To confine dental care utilisation only for treatment purposes, we limited our outcome variables to the incidence of dental caries using ICD-10 code of K02 (Analysis S1). Since dental care utilisation for preventive measures was also reported to occur over six months [20, 21], we performed an additional analysis that excluded recipients who had received dental care in the first six months (Analysis S2). The robust standard error estimator was adopted for all statistical analyses to calculate 95\% CIs. All the analyses were performed using STATA SE Ver.16.2 (Stata Corp., College Station, TX, USA).

\section{Results}

We obtained the data of 6016 people on public assistance, 4497 recipients did not use dental care during the first three months of the observational period (Fig. 1). Among them, 2281 (50.7\%) were women, 859 (19.0\%) had jobs, $392(8.7 \%)$ had mental disabilities, and 124 (2.8\%) were immigrants. Regarding the recipients' oral health, 839 (18.7\%) utilised dental care during the observational period (Table 1, Figure S1). The univariable modified Poisson regression analysis showed that recipients who were young, women, immigrants, employed, and certified with mental disabilities had higher incidences of dental care utilisation (Table S1).

In the multivariable modified Poisson regression analyses, the results of Analysis 1 showed that recipients who were young, women, immigrants, certified with 
Table 1 Characteristics of the study participants and the recipients on dental care services

\begin{tabular}{|c|c|c|c|c|c|}
\hline \multirow[t]{2}{*}{ Character } & \multirow[t]{2}{*}{ Category } & \multirow{2}{*}{$\begin{array}{l}\text { Analysis } 1 \\
\text { Total participants } \\
(N=5717) \\
N(\%)\end{array}$} & $\begin{array}{l}\text { Participants } \\
\text { on dental } \\
\text { care } \\
(n=2059)\end{array}$ & \multirow{2}{*}{$\begin{array}{l}\text { Analysis } 2 \\
\text { Population at risk } \\
(N=4497) \\
\mathrm{N}(\%)\end{array}$} & \multirow{2}{*}{$\begin{array}{l}\text { Participants } \\
\text { on dental } \\
\text { care } \\
(n=839) \\
\mathrm{n}, \% \text { for } \mathrm{N}\end{array}$} \\
\hline & & & $\mathrm{n}, \%$ for $\mathrm{N}$ & & \\
\hline Age & Mean (SD) & $62.6(15.9)$ & $60.2(15.8)$ & $63.0(15.9)$ & $59.2(15.6)$ \\
\hline \multirow[t]{2}{*}{ Sex } & Male & $2790(48.8)$ & $950,34.1 \%$ & $2216(49.3)$ & $376,17.0 \%$ \\
\hline & Female & $2927(51.2)$ & $1109,37.9 \%$ & $2281(50.7)$ & $463,20.3 \%$ \\
\hline \multirow[t]{2}{*}{ Living alone } & Yes & $3762(65.8)$ & $1353,36.0 \%$ & $2943(65.4)$ & $534,18.1 \%$ \\
\hline & No & $1955(34.2)$ & $706,36.1 \%$ & $1554(34.6)$ & $305,19.6 \%$ \\
\hline \multirow[t]{2}{*}{ Working status } & Yes & $1088(19.0)$ & $433,39.8 \%$ & $856(19.0)$ & $201,23.5 \%$ \\
\hline & No & $4629(81.0)$ & $1626,35.1 \%$ & 3641 (81.0) & $638,17.5 \%$ \\
\hline \multirow[t]{2}{*}{ Nationality } & Japanese & $5558(97.2)$ & $1986,35.7 \%$ & $4373(97.2)$ & $801,18.3 \%$ \\
\hline & Other & $159(2.8)$ & $73,45.9 \%$ & $124(2.8)$ & $38,30.6 \%$ \\
\hline \multirow[t]{3}{*}{ Long-term care status } & None & $4896(85.6)$ & $1762,36.0 \%$ & $3870(86.1)$ & $736,19.0 \%$ \\
\hline & Support required & $202(3.5)$ & $62,30.7 \%$ & 163 (3.6) & $23,14.1 \%$ \\
\hline & Care needs & $619(10.8)$ & $235,38.0 \%$ & $464(10.3)$ & $80,17.2 \%$ \\
\hline \multirow[t]{4}{*}{ Disabilities certificate } & None & $4645(81.2)$ & $1605,34.6 \%$ & $3709(82.5)$ & $669,18.0 \%$ \\
\hline & Mental disability & $536(9.4)$ & $246,45.9 \%$ & $392(8.7)$ & $102,26.0 \%$ \\
\hline & Intellectual disability & $83(1.5)$ & $33,39.8 \%$ & $59(1.3)$ & $9,15.3 \%$ \\
\hline & Physical disability & $453(7.9)$ & $175,38.6 \%$ & $337(7.5)$ & $59,17.5 \%$ \\
\hline \multirow[t]{2}{*}{ Municipality } & A & $4213(73.7)$ & $1537,36.5 \%$ & 3310 (73.6) & $634,19.2 \%$ \\
\hline & B & 1504 (26.3) & $522,34.7 \%$ & $1187(26.4)$ & $205,17.3 \%$ \\
\hline
\end{tabular}

Analysis 1 includes all eligible participants, and Analysis 2 includes population at risk after excluding cases at the first three months. SD Standard Deviation

mental disabilities, certified with 'care-needs' level of long-term care, and those who lived alone had high incidences of dental care utilisation (Table 2). The results of Analysis 2 showed that recipients who were young (IR, 0.87 (by 10 -year-age groups); $95 \% \mathrm{CI}, 0.84-0.91$ ), women (IR, 1.22; 95\% CI, 1.08-1.38), immigrants (IR, 1.53; 95\% CI, 1.16-2.01), and certified with mental disabilities (IR, 1.30; 95\% CI, 1.08-1.56) were associated with high incidences of dental care utilisation. Recipients, who lived alone, were employed, and who needed long-term care had a slightly high incidence of dental care utilisation (Table 2). Our sensitivity analysis (Analysis S1) showed that recipients who were women and certified with mental disabilities were associated with high incidences of dental caries (IR, 1.30; 95\% CI, 1.14-1.49 and IR, 1.32; 95\% CI, 1.09-1.59; respectively); however, there was no strong association between nationality and dental caries diagnosis (Additional File 2). Moreover, the results of Analysis S2 that excluded users from dental services in the first six months showed similar results as that of Analysis 2 (Additional File 3).

\section{Discussion}

Our study found that among public assistance recipients in Japan, the incidence of dental care utilisation was high among young people, women, immigrants, and those with mental disability certificates. This was the first study that demonstrated sociodemographic inequities in dental care utilisation among adult public assistance recipients whose dental care utilisations and minimum incomes were financially ensured. The strength of this study was that by using existing standardised databases without missing data, we identified the inequities in dental care utilisation among public assistance recipients who are usually difficult to reach through standard social surveys.

\section{Findings in context}

The high incidence of dental care utilisation among the younger recipients observed in this study can be attributed to the following factors. First, older people who have lost their teeth may not perceive the need for dental care services, except for dentures [22]. Second, younger recipients might have higher oral health literacy and accessibility to dental care than older recipients. The findings that the female recipients and those with mental disabilities had a higher incidence of dental care utilisation were consistent with the results of other recent studies [23-25]. Women may have a greater preference for maintaining oral health 
Table 2 Adjusted incidence ratios for the incidence of dental care utilization among public assistance recipients

\begin{tabular}{|c|c|c|c|}
\hline & & $\begin{array}{l}\text { Analysis } 1 \\
\text { IR, }(95 \% \text { Cl) }\end{array}$ & $\begin{array}{l}\text { Analysis } 2 \\
\text { IR, }(95 \% \text { Cl) }\end{array}$ \\
\hline Age & by 10 year & $0.90(0.88-0.93)$ & $0.87(0.84-0.91)$ \\
\hline \multirow[t]{2}{*}{ Sex } & Male & Ref & Ref \\
\hline & Female & $1.14(1.06-1.22)$ & $1.22(1.08-1.38)$ \\
\hline \multirow[t]{2}{*}{ Working status } & No & Ref & Ref \\
\hline & Yes & $1.03(0.94-1.13)$ & $1.15(0.99-1.34)$ \\
\hline \multirow[t]{2}{*}{ Living alone } & No & Ref & Ref \\
\hline & Yes & $1.08(1.00-1.16)$ & $1.06(0.93-1.21)$ \\
\hline \multirow[t]{2}{*}{ Nationality } & Japanese & Ref & Ref \\
\hline & Other & $1.25(1.05-1.49)$ & $1.53(1.16-2.01)$ \\
\hline \multirow[t]{3}{*}{ Long-term care status } & None & Ref & Ref \\
\hline & Support required & $0.99(0.80-1.23)$ & $0.94(0.64-1.40)$ \\
\hline & Care needs & $1.26(1.12-1.41)$ & $1.20(0.95-1.50)$ \\
\hline \multirow[t]{4}{*}{ Disabilities certificate } & None & Ref & Ref \\
\hline & Mental disability & $1.22(1.10-1.36)$ & $1.30(1.08-1.56)$ \\
\hline & Intellectual disability & $0.98(0.75-1.29)$ & $0.65(0.36-1.19)$ \\
\hline & Physical disability & $1.11(0.98-1.26)$ & $1.02(0.80-1.31)$ \\
\hline \multirow[t]{2}{*}{ Municipality } & A & Ref & Ref \\
\hline & B & $0.94(0.87-1.02)$ & $0.91(0.79-1.06)$ \\
\hline
\end{tabular}

Analysis 1 includes all eligible participants, and Analysis 2 includes population at risk after excluding cases at the first three months. $I R$ Incidence Ratio, $C I$ Confidence Interval

and aesthetic appearance than men due to the societal norms [23-25], resulting in their higher use of dental care services than men. It is conceivable that we might have overestimated the usage of dental care services among female recipients because our outcome depended on recipients' dental care utilisations. Moreover, the reduced motivation of patients with mental disabilities or severe mental health disorders to care for their oral health may explain the association between mental disability and poor oral health [26, 27]. Reduced protective factors for oral diseases as side effects of medications (such as decreased saliva secretion) can also explain the association [28].

There may be several possible explanations for the higher incidence of dental care utilisation among immigrants than the Japanese recipients. First, free dental care associated with the public assistance programme might have inflated immigrants' dental care attendance, as payment for dental services may be needed in their own countries. Second, our findings were consistent with those of a recent study on non-recipient immigrants. Oral diseases and dental care utilisation were more prevalent among immigrants than the Japanese [29, 30]. Baseline disease levels may be worse among immigrant recipients of public assistance than among Japanese recipients. Third, immigrant recipients of public assistance may also use more dental care services for preventive measures than for treatment purposes. Our sensitivity analysis that showed the absence of a strong association between nationality and dental care utilisation for the treatment of dental caries underscored this hypothesis. The frequency of dental visits for symptoms of dental caries may be similar between Japanese and immigrant recipients. In this context, Japanese recipients might be underserved by dental care services for preventive measures. Finally, immigrant recipients have also been reported to use medical care services more frequently than Japanese recipients [31]. Immigrant recipients may experience social isolation, which may lead to their increased demands for support by healthcare professionals, including dental care providers. Further studies are required to examine the reasons for high incidences of dental visits among immigrants.

Although this study could not identify the reason for not using dental care services, according to the national survey of dental diseases, approximately $30 \%$ of Japanese adults have dental diseases that require treatment [22]. Considering that the study population faces poverty that is related to poor oral health [13], there may be a larger proportion of people who did not receive dental care despite their unpreferable oral health conditions among the public assistance recipients. Recipients who did not use dental care services in this study may have underutilised dental care. 


\section{Practice and policy implications}

Our study provides novel evidence that sociodemographic inequities in dental care utilisation are still prevalent among public assistance recipients in Japan, even though they are assured free dental care access and minimum income by the government welfare programme. Individual socioeconomic backgrounds may be involved in determining dental care utilisation. Since oral health strongly influences individual and societal burdens, identifying population segments at risk of underserved dental care and prioritising preventive and treatment activities may be effective $[32,33]$. Dental care providers and policymakers should also consider designing dental care interventions using population-based approaches. Although the Japanese government will implement a mandated health management programme for public assistance recipients in 2021 [34], this programme does not include oral healthcare. Thus, the government also needs to provide an additional oral health management programme to public assistance recipients.

\section{Limitations}

Our study had several limitations. First, although we used longitudinal data, there was still the possibility of reverse causation. Some people may have developed severe oral diseases and other illnesses, which would have resulted in financial difficulties and the subsequent need for public assistance. Nonetheless, the results of the analyses that removed the incidence of dental care utilisation during the first three months minimised the risk of reverse causation. Second, our use of medical assistance claim data might have over- or under-estimated the incidence of dental care utilisation. The incidence was only evaluated for utilisation of dental care services; thus, recipients who experienced severe health conditions or social isolation might not have been able to access dental care services, which may have resulted in differential misclassification. Third, there were important factors that were not evaluated in this study, such as the severity of diseases and what the dental treatments entailed, and this may have potentially biased our findings. For example, we could not differentiate between dental services used for preventive or treatment purposes from the data. Finally, since this study used data from only two municipalities in Japan, the generalisability of our findings to other populations may be limited.

\section{Conclusion}

Our study suggests that public assistance recipients who are young, female, immigrants, and have mental disabilities have a high incidence of dental care utilisation. Sociodemographic inequities in the use of dental care services exist despite free access to dental services and minimum income protection amongst public assistance recipients in Japan. Providing targeted preventive and curative dental care for underserved populations is required. Further investigations using detailed information about broader sociodemographic factors, the severity of the oral health conditions, and dental treatments received are warranted.

\section{Abbreviations \\ IR: Incidence ratio; Cl: Confidence interval; ICD-10: International Classification of Disease, Tenth Edition}

\section{Supplementary Information}

The online version contains supplementary material available at https://doi. org/10.1186/s12939-021-01473-8.

Additional file 1: Table S1. Crude incidence ratios (IR) and 95\% confidence intervals $(\mathrm{Cl})$ for the incidence of dental care utilisation among public assistance recipients.

Additional file 2: Table S2. Adjusted incidence ratios (IR) and 95\% confidence intervals $(\mathrm{Cl})$ for the incidence of dental caries diagnosis among public assistance recipients (Analysis S1).

Additional file 3: Table S3. Adjusted incidence ratios (IR) and 95\% confidence intervals $(\mathrm{Cl})$ for incidence of the dental care utilisation excluding cases at the first six months.

Additional file 4: Figure S1. Distribution of the cumulative incidence of dental care utilisation among public assistance recipients.

\section{Acknowledgements}

We would like to thank Editage [http://www.editage.com] for editing and reviewing this manuscript.

\section{Authors' contributions}

DN, KU, SK, and NK conceptualised and designed the study. DN analysed the data and prepared the manuscript. KU, SK, and JA reviewed the manuscript. NK finalised the manuscript. All authors read and approved the final manuscript.

\section{Funding}

This study was supported by the Japan Society for the Promotion of Science KAKENHI grants (17 K19793, 18H04071, 20 K20774) and Kitanihon Computer Service Co. Ltd. (KITACOM), who provided the data used. The research funding bodies had no discretion and involvement in our study protocol, analysis, interpretation of the results, or the submission of this manuscript.

\section{Availability of data and materials}

The data used in this study were obtained from the participating municipalities in Japan; however, there are restrictions regarding the availability of these data, which were used under licence for the current study, and are not publicly available. The data are available from the authors upon reasonable request, with the permission of the municipalities.

\section{Declarations}

Ethics approval and consent to participate

The welfare offices of the municipalities agreed to provide anonymised data to the authors via a system company, which had provided management software for the public assistance database to the municipality welfare offices. The study protocol was approved by the Ethics Committee of the Graduate School of Medicine, University of Tokyo (Approval No: 11503).

\section{Consent for publication}

Not applicable.

\section{Competing interests}

Daisuke Nishioka, Keiko Ueno, Shiho Kino, and Jun Aida declare no competing interests associated with this manuscript. Naoki Kondo conducted collaborative research with Kitanihon Computer Service Co. Ltd. 
(KITACOM) that provided the data used in the present study. Naoki Kondo received a research fund and a scholarship donation from KITACOM.

\begin{abstract}
Author details
'Department of Medical Statistics, Research \& Development Center, Osaka Medical and Pharmaceutical University, Osaka, Japan. ${ }^{2}$ Department of Health and Social Behavior, Graduate School of Medicine, The University of Tokyo, Kyoto, Japan. ${ }^{3}$ Department of Social Epidemiology, Graduate School of Medicine and School of Public Health, Kyoto University, Floor 2, Science Frontier Laboratory, Yoshida-konoe-cho, Sakyo-ku, Kyoto-shi, Kyoto 606-8315, Japan. ${ }^{4}$ Department of Oral Health Promotion, Graduate School of Medical and Dental Sciences, Tokyo Medical and Dental University, Tokyo, Japan. ${ }^{5}$ Division for Regional Community Development, Liaison Center for Innovative Dentistry, Graduate School of Dentistry, Tohoku University, Sendai, Japan. ${ }^{6}$ Institute for Future Initiatives, The University of Tokyo, Tokyo, Japan. ${ }^{7}$ Japan Agency for Gerontological Evaluation Study (JAGES Agency), Tokyo, Japan.
\end{abstract}

Received: 4 November 2020 Accepted: 10 May 2021

Published online: 16 June 2021

\section{References}

1. Peres MA, Macpherson LMD, Weyant RJ, et al. Oral diseases: a global public health challenge. Lancet. 2019;394(10194):249-60.

2. James SL, Abate D, Abate KH, et al. Global, regional, and national incidence, prevalence, and years lived with disability for 354 diseases and injuries for 195 countries and territories, 1990-2017: a systematic analysis for the global burden of disease study 2017. Lancet. 2018;392(10159):1789-858.

3. Jin $\sqcup$, Lamster IB, Greenspan JS, et al. Global burden of oral diseases: emerging concepts, management and interplay with systemic health. Oral Dis. 2016;22(7):609-19.

4. Kandelman D, Petersen PE, Ueda H. Oral health, general health, and quality of life in older people. Spec Care Dentist. 2008;28(6):224-36.

5. Petersen PE, Kandelman D, Arpin S, et al. Global oral health of older people - call for public health action. Community Dent Health. 2010;27(4):257-67.

6. World Health Organization. A conceptual framework for action on the social determinants of health. 2010. https://www.who.int/sdhconference/ resources/ConceptualframeworkforactiononSDH_eng.pdf. Accessed 24 Sep 2020.

7. Lee SM, Song YS, Kim YN, et al. The influence of the mother's nationality on adolescent's subjective oral health status-using propensity score matching. J Korean Acad Oral Health. 2018;42(2):46-51.

8. Liang J, Wu B, Plassman B, et al. Racial disparities in trajectories of dental caries experience. Community Dent Oral Epidemiol. 2013;41(6):517-25.

9. Chen CC, Chiou SJ, Ting CC, et al. Immigrant-native differences in cariesrelated knowledge, attitude, and oral health behaviors: a cross-sectional study in Taiwan. BMC Oral Health. 2014;14(1):3.

10. Persson GR, Persson RE, Hollender LG, et al. The impact of ethnicity, gender, and marital status on periodontal and systemic health of older subjects in the trials to enhance Elders' teeth and Oral health (TEETH). J Periodontol. 2004;75(6):817-23.

11. Sundby A, Petersen PE. Oral health status in relation to ethnicity of children in the municipality of Copenhagen, Denmark. Int J Paediatr Dent. 2003; 13(3):150-7.

12. Kiyak HA, Kamoh A, Persson RE, et al. Ethnicity and oral health in community-dwelling older adults. Gen Dent. 2002;50(6):513-8.

13. Northridge ME, Kumar A, Kaur R. Disparities in access to Oral health care. Annu Rev Public Health. 2020:41:513-35.

14. Burr JA, Lee HJ. Social relationships and dental care service utilization among older adults. J Aging Health. 2013;25(2):191-220.

15. Tellez M, Zini A, Estupiñan-Day S. Social determinants and oral health: an update. Curr Oral Health Rep. 2014;1(3):148-52.

16. Sakamoto H, Rahman M, Nomura S, et al. Japan health system review. 2018. World Health Organization. Regional Office for South-East Asia. https://apps. who.int/iris/handle/10665/259941. (Accessed July 21, 2020).

17. Ministry of Internal Affairs and Communications. List of Major Financial Indicators for Local Governments in Fiscal Year 2016 (in Japanese), 2016. https://www.soumu.go.jp/main_content/000264701.pdf. Accessed 13 Apr 2020.
18. World Health Organization. International Statistical Classification of Diseases and Related Health Problems, 10th Revision (ICD-10). https://www.who.int/ classifications/icd/icdonlineversions/en/. Accessed 24 Sep 2020.

19. Zou G. A Modified poisson regression approach to prospective studies with binary data. Am J Epidemiol. 2004;159(7):702-06. https://doi.org/10.1093/aje/ kwh090.

20. Riley P, Worthington HV, Clarkson JE, et al. Recall intervals for oral health in primary care patients. Cochrane Database Syst Rev. 2013;(12):Cd004346.

21. Japan Dental Association. Public Attitude Survey on Dental Care (in Japanese). https://www.jda.or.jp/jda/release/pdf/DentalMedicalAwa renessSurvey_h30.pdf Accessed 24 Sep 2020.

22. Ministry of Health, Labour, and Welfare. Survey on dental diseases in 2016 (in Japanese). https://www.mhlw.go.jp/toukei/list/62-28.html. Accessed 13 Apr 2020.

23. Furuta $M$, Ekuni $D$, Irie $K$, et al. Sex differences in gingivitis relate to interaction of oral health behaviors in young people. J Periodontol. 2011; 82(4):558-65. https://doi.org/10.1902/jop.2010.100444.

24. Hodge HC, Holloway PJ, Bell CR. Factors associated with toothbrushing behaviour in adolescents. Br Dent J. 1982;152(2):49-51.

25. Sakki TK, Knuuttila ML, Anttila SS. Lifestyle, gender and occupational status as determinants of dental health behavior. J Clin Periodontol. 1998;25(7): 566-70. https://doi.org/10.1111/j.1600-051x.1998.tb02489.x.

26. Kisely $\mathrm{S}$, Baghaie $H$, Lalloo $\mathrm{R}$, et al. A systematic review and meta-analysis of the association between poor oral health and severe mental illness. Psychosom Med. 2015;77(1):83-92. https://doi.org/10.1097/PSY. 0000000000000135 .

27. Nielsen J, Munk-Jorgensen P, Skadhede S, et al. Determinants of poor dental care in patients with schizophrenia: a historical, prospective database study. J Clin Psychiatry. 2011;72(2):140-3. https://doi.org/10.4088/JCP.09m05318yel.

28. Lalloo R, Kisely S, Amarasinghe $H$, et al. Oral health of patients on psychotropic medications: a study of outpatients in Queensland. Australias Psychiatry. 2013;21(4):338-42. https://doi.org/10.1177/1039856213486308.

29. Ohsato A, Abe M, Ohkubo K, et al. A comparative study of Oral health status between international and Japanese University student patients in Japan. Healthcare. 2018;6(2):52.

30. Otsuru J, Abe S, Shinada K, et al. Oral health status in migrant workers (in Japanese). Dent Health. 2003;53(1):30-7. https://doi.org/10.5834/jdh.53.1_30.

31. Nishioka D, Saito J, Ueno K, et al. Frequent outpatient attendance among people on the governmental welfare programme in Japan: assessing both patient and supplier characteristics. BMJ Open. 2020;10(10):e038663. https:// doi.org/10.1136/bmjopen-2020-038663.

32. Chazin S, Glover J. A community framework for addressing social determinants of Oral health for low-income populations: Center for Health Care Strategies, Inc; 2017.

33. Borrell LN. Oral health inequities: an AJPH supplement to help close the gap. Am J Public Health. 2017;107(S1):S6-7.

34. The Ministry of Health, Labour, and Welfare. Appropriate medical assistance and health management for people on public assistance (in Japanese). https://www.mhlw.go.jp/file/05-Shingikai-12601000-Seisakutoukatsukan-Sa njikanshitsu_Shakaihoshoutantou/0000169132_5.pdf. Accessed 24 Sep 2020

\section{Publisher's Note}

Springer Nature remains neutral with regard to jurisdictional claims in published maps and institutional affiliations.

Ready to submit your research? Choose BMC and benefit from:

- fast, convenient online submission

- thorough peer review by experienced researchers in your field

- rapid publication on acceptance

- support for research data, including large and complex data types

- gold Open Access which fosters wider collaboration and increased citations

- maximum visibility for your research: over $100 \mathrm{M}$ website views per year

At $\mathrm{BMC}$, research is always in progress.

Learn more biomedcentral.com/submission 